were on csDMARDs only, $616(42 \%)$ were on first line biologic/targeted synthetic (ts)DMARD therapy, and $172(12 \%)$ were on second line biologic/tsDMARD therapy. The relationship between skin severity and joint activity was statistically significant $(p<0.0001)$ with a correlation of 0.183 . Results were similar when adjusting separately for treatment and for duration of PsA and PsO. Greater age, female gender, higher dactylitis count, not achievement of MDA, higher HAQ, and patient reported pain and fatigue affected the relationship.

Conclusions: The relationship between skin severity and joint activity is statistically significant and varies by age, gender, MDA, HAQ, and patient reported pain and fatigue. This suggests degree of skin involvement is important to take into account when evaluating PsA patients.

References:

[1] Gottlieb AB, Mease PJ, Mark Jackson J, Eisen D, Amy Xia H, Asare C, Stevens SR: Clinical characteristics of psoriatic arthritis and psoriasis in dermatologists' offices. J Dermatolog Treat 2006;17:279-287.

[2] Jones SM, Armas JB, Cohen MG, Lovell CR, Evison G, McHugh NJ: Psoriatic arthritis: outcome of disease subsets and relationship of joint disease to nail and skin disease. Br J Rheumatol 1994;33:834-839.

[3] Cohen MR, Reda DJ, Clegg DO: Baseline relationships between psoriasis and psoriatic arthritis: analysis of 221 patients with active psoriatic arthritis. Department of Veterans Affairs Cooperative Study Group on Seronegative Spondyloarthropathies. J Rheumatol 1999;26:1752-1756.

Acknowledgements: Corrona, LLC has been supported through contracted subscriptions in the last two years by AbbVie, Amgen, AstraZeneca, BMS, Crescendo, Eli Lilly and Company, Genentech, GSK, Horizon Pharma USA, Janssen, Momenta Pharmaceuticals, Novartis, Pfizer, Roche and UCB.

Disclosure of Interest: P. Mease Grant/research support from: Celgene, Novartis, Abbvie, Amgen, BMS, Janssen, Lilly, Pfizer, Sun, UCB, Consultant for: AbbVie, Amgen, BMS, Crescendo, Celgene, Corrona, Demira, Janssen, Lilly, Merck, Novartis, Pfizer, UCB, Sun, Zynerba, Speakers bureau: Abbvie, Amgen, BMS, Celgene, Crescendo, Genentech, Janssen, Novartis, Pfizer, UCB, C. Etzel Consultant for: Merk, Employee of: Corrona, LLC, J. Lisse Shareholder of: Eli Lilly and Company, Employee of: Eli Lilly and Company, A. Armstrong Grant/research support from: AbbVie, Janssen, Lilly; speaker's bureau: AbbVie, Lilly, Consultant for: AbbVie, Amgen, Janssen, Merck, Lilly, Celgene, Novartis, and Pfizer, W. Huster Shareholder of: Eli Lilly and Company, Employee of: Eli Lilly and Company, S. Rebello Employee of: Corrona, LLC, R. Dodge Employee of: Corrona, LLC, T. Muram Shareholder of: Eli Lilly and Company, Employee of: Eli Lilly and Company, S. Al Sawah-Folian Shareholder of: Eli Lilly and Company, Employee of: Eli Lilly and Company, M. Murage Shareholder of: Eli Lilly and Company, Employee of: Eli Lilly and Company, J. Greenberg Shareholder of: Corrona, LLC, Consultant for: Genentech, Janssen, Novartis and Pfizer, Eli Lilly, Employee of: Corrona, LLC, W. Malatestinic Shareholder of: Eli Lilly and Company, Employee of: Eli Lilly and Company

DOI: 10.1136/annrheumdis-2017-eular.1938

\section{AB0784 EFFECTIVENESS OF ANTI-TNFS ON DACTYLITIS AND ENTHESITIS IN PATIENTS WITH PSORIATIC ARTHRITIS: RESULTS FROM THE CORRONA PSORIATIC ARTHRITIS/SPONDYLOARTHRITIS REGISTRY}

P.J. Mease ${ }^{1,2}$, R. Singh ${ }^{3}$, K. Douglas ${ }^{3}$, D. Hua ${ }^{4}$, H.J. Litman ${ }^{4}$, C. Karki ${ }^{4}$, J. Griffith ${ }^{3} .{ }^{1}$ Swedish Medical Center; ${ }^{2}$ University of Washington, Seattle, ${ }^{3}$ AbbVie, Inc., Abbott Park; ${ }^{4}$ Corrona, LLC, Southborough, United States

Background: Dactylitis and enthesitis are common disease manifestations encountered in nearly $10-30 \%$ of patients with psoriatic arthritis (PsA). Previous clinical trial data suggests that anti-tumor necrosis factors (aTNFs) are effective in controlling dactylitis and enthesitis among PsA patients, however there are limited data from real world studies.

Objectives: To evaluate the effectiveness of aTNFs on dactylitis and enthesitis in patients with PsA enrolled in Corrona, a large US observational cohort of patients with PsA and spondyloarthritis.

Methods: Adult PsA patients who initiated or were currently on an aTNF at registry enrollment (baseline) between 3/2013-9/2016 and had a 12 month follow-up visit were included. Dactylitis was defined as a non-zero total dactylitis score on a scale $0-20$ and enthesitis was defined by a non-zero score on the SPARCC enthesitis index, $0-16$. The primary outcome was change in dactylitis and enthesitis scores at 12 months from baseline. Descriptive analysis of patient characteristics at baseline was examined and change in outcomes was evaluated using t-tests.

Results: There were 28 patients with dactylitis and 77 patients with enthesitis who met the inclusion criteria. Patients with dactylitis and enthesitis had a mean (SD): age of 48.2 (14.8) and 53.5 (11.5) years, body mass index of $30.8(6.6)$ and $31.4(7.6)$, disease duration of $9.3(9.1)$ and $8.1(7.7)$ years, and $28.6 \%$ and $45.5 \%$ were on methotrexate combination therapy respectively. Patients had a mean clinical disease activity index of 15.1 in both groups, $40.0 \%$ and $17.1 \%$ were in minimal disease activity, mean (SD): body surface area was $4.4(4.4)$ and 5.2 (9.7), pain was 33.1 (29.5) and 43.3 (27.5) on a visual analogue scale (VAS) of $0-100$, and more than $80 \%$ and $90 \%$ of patients had some morning stiffness in the dactylitis and enthesitis groups, respectively. At 12 months from baseline, there were significant improvements in both dactylitis and enthesitis scores in patients with PsA treated with aTNFs (Table).
Table: Primary outcomes in PSA patients on aTNFs at 12 months from baseline

\begin{tabular}{|c|c|c|c|c|}
\hline & At enrollment & $\begin{array}{l}\text { At } 12 \text { month } \\
\text { visit }\end{array}$ & $\begin{array}{c}\text { Change in score } \\
\text { (enrollment -12 } \\
\text { month visit }\end{array}$ & p-value* \\
\hline Dactylitis Count $(0-20)$ & $n=28$ & $n=28$ & $n=28$ & \\
\hline Mean $( \pm S D)$ & $2.1( \pm 1.5)$ & $0.5( \pm 1.1)$ & $-1.6( \pm 1.8)$ & 0.001 \\
\hline SPARCC Enthesitis Count (0-16) & $n=77$ & $n=77$ & $\mathrm{n}=77$ & \\
\hline Mean $( \pm S D)$ & $4.1( \pm 3.2)$ & $1.9( \pm 2.8)$ & $-2.2( \pm 3.2)$ & $<0.001$ \\
\hline
\end{tabular}

counts differs from 0 .

Conclusions: In this clinical registry, aTNF therapy significantly improved both dactylitis and enthesitis at 12 months. Further evaluation of secondary outcomes and larger studies with comparator cohorts will further validate the effectiveness of aTNFs in improving the outcomes in PsA patients.

Acknowledgements: This study is sponsored by Corrona, LLC. The Corrona, LLC has been supported through contracted subscriptions in the last two years by AbbVie, Amgen, BMS, Crescendo, Eli Lilly and Company, Genentech, GSK, Horizon Pharma USA, Janssen, Momenta Pharmaceuticals, Novartis, Pfizer, Roche and UCB. The design, study conduct, and financial support for the study was provided by AbbVie. AbbVie participated in the interpretation of data, review, and approval of the abstract.

Disclosure of Interest: P. Mease Grant/research support from: Celgene, Novartis, Abbvie, Amgen, BMS, Janssen, Lilly, Pfizer, UCB, Consultant for: Celgene, Corrona, Merck, Novartis, Abbvie, Amgen, BMS, Crescendo, Genentech, Janssen, Lilly, Merck, Pfizer, UCB, Speakers bureau: Abbvie, Amgen, BMS, Crescendo, Genentech, Janssen, Lilly, Novartis, Pfizer, UCB, R. Singh Shareholder of: AbbVie, Inc, Employee of: AbbVie, Inc, K. Douglas Shareholder of: AbbVie, Inc, Employee of: AbbVie, Inc, D. Hua Employee of: Corrona, LLC, H. Litman Employee of: Corrona, LLC, C. Karki Employee of: Corrona, LLC, J. Griffith Shareholder of: AbbVie, Inc, Employee of: AbbVie, Inc

DOI: 10.1136/annrheumdis-2017-eular.1532

\section{AB0785 CONSISTENT SAFETY PROFILE WITH UP TO 4 YEARS OF APREMILAST TREATMENT: ANALYSIS OF DATA FROM 1493 PATIENTS WITH PSORIATIC ARTHRITIS IN 3 LARGE, PHASE III, LONG-TERM STUDIES}

P.J. Mease ${ }^{1}$, D.D. Gladman ${ }^{2}$, J.J. Gomez-Reino ${ }^{3}$, S. Hall ${ }^{4}$, A. Kavanaugh ${ }^{5}$, E. Lespessailles ${ }^{6}$, G. Schett ${ }^{7}$, M. Paris ${ }^{8}$, L. Teng ${ }^{8}$, J. Wollenhaupt ${ }^{9} .{ }^{1}$ Swedish Medical Center and University of Washington School of Medicine, Seattle, United States; ${ }^{2}$ Toronto Western Research Institute, Toronto, Canada: ${ }^{3}$ Hospital Clínico Universitario, Santiago, Spain; ${ }^{4}$ Monash University, CabriniHealth, Melbourne, Australia; ${ }^{5}$ University of California, San Diego, School of Medicine, la Jolla, United States; ${ }^{6}$ University of Orléans, Orléans, France; ${ }^{7}$ University of Erlangen-Nuremberg, Erlangen, Germany; ${ }^{8}$ Celgene Corporation, Summit, United States; ${ }^{9}$ Schön Klinik Hamburg Eilbek, Hamburg, Germany

Background: Apremilast (APR), an oral phosphodiesterase 4 inhibitor, regulates immune activity in psoriatic arthritis (PsA) patients. Safety data were pooled from the phase 3 PALACE 1,2, and 3 studies.

Objectives: Evaluate the long-term safety of APR treatment for up to 4 years in patients with active PsA despite prior conventional DMARDs and/or biologics.

Methods: Patients were randomized at baseline (1:1:1) to placebo (PBO), APR 30 mg BID (APR30), or APR 20 mg BID (APR20). PBO patients were re-randomized

\begin{tabular}{|c|c|c|c|c|}
\hline & \multicolumn{4}{|c|}{ APR-Exposure Period ${ }^{*}$} \\
\hline & $\begin{array}{c}\text { Weeks } \\
0 \text { to } \leq 52 \\
\end{array}$ & $\begin{array}{c}\text { Weeks } \\
>52 \text { to } \leq 104\end{array}$ & \begin{tabular}{c|} 
Weeks \\
$>104$ to $\leq 156$
\end{tabular} & \begin{tabular}{|c|} 
Weeks \\
$>156$ to $\leq 208$ \\
\end{tabular} \\
\hline & $\begin{array}{l}\text { APR30 } \\
n=721\end{array}$ & $\begin{array}{l}\text { APR30 } \\
n=520\end{array}$ & $\begin{array}{l}\text { APR30 } \\
n=443\end{array}$ & $\begin{array}{l}\text { APR30 } \\
n=401\end{array}$ \\
\hline \multicolumn{5}{|l|}{ Patients, $n(\%)$} \\
\hline $21 \mathrm{AE}$ & $524(72.7)$ & $316(60.8)$ & $284(64.1)$ & $234(58.4)$ \\
\hline $21 \mathrm{SAE}$ & $47(6.5)$ & $35(6.7)$ & $40(9.0)$ & $28(7.0)$ \\
\hline AE leading to drug withdrawal & $56(7.8)$ & $13(2.5)$ & $7(1.6)$ & $7(1.7)$ \\
\hline Death & $0(0.0)$ & $15(0.2)$ & $0(0.0)$ & $2^{ \pm 1}(0.5)$ \\
\hline \multicolumn{5}{|l|}{ AEs in $25 \%$ of patients, $n(\%)$} \\
\hline Diarrhea & $112(15.5)$ & $20(3.8)$ & $12(2.7)$ & $4(1.0)$ \\
\hline Nausea & $108(15.0)$ & $11(2.1)$ & $10(2.3)$ & $3(0.7)$ \\
\hline Headache & $75(10.4)$ & $17(3.3)$ & $12(2.7)$ & $7(1.7)$ \\
\hline Upper respiratory tract infection & $60(8.3)$ & $27(5.2)$ & $24(5.4)$ & $21(5.2)$ \\
\hline Nasopharyngitis & $41(5.7)$ & $31(6.0)$ & $20(4.5)$ & $26(6.5)$ \\
\hline \multicolumn{5}{|c|}{ Select marked abnormalities in clinical laboratory parameters, $\mathrm{n} / \mathrm{m}$ (\%) } \\
\hline Alanine aminotransferase $>3 \times$ ULN & $9 / 713(1.3)$ & $2 / 518(0.4)$ & $2 / 442(0.5)$ & $1 / 401(0.2)$ \\
\hline Creatinine $>1.7 \times$ ULN & $1 / 713(0.1)$ & $0 / 518(0.0)$ & $0 / 442(0.0)$ & $1 / 401(0.2)$ \\
\hline Leukocytes $<1.5,10^{9} /$ & $0 / 713(0.0)$ & $0 / 517(0.0)$ & $0 / 442(0.0)$ & $0 / 401(0.0)$ \\
\hline Neutrophils $<1,10^{9}$ L & $2 \pi 13(0.3)$ & $3 / 517(0.6)$ & $2 / 442(0.5)$ & $2 / 401(0.5)$ \\
\hline Platelets $<75,10^{\circ} 几$ & $0 / 713(0.0)$ & $0 / 517(0.0)$ & $1 / 441(0.2)$ & $0 / 399(0.0)$ \\
\hline Hemoglobin, male $<10.5 \mathrm{~g} / \mathrm{dL}$, female $<8.5 \mathrm{~g} / \mathrm{dL}$ & $5 / 713(0.7)$ & $4 / 517(0.8)$ & $5 / 442(1.1)$ & $5 / 401(1.2)$ \\
\hline \multicolumn{5}{|c|}{ 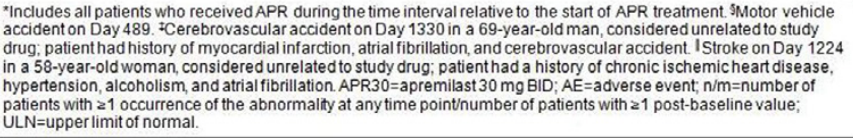 } \\
\hline
\end{tabular}


to APR30 or APR20 at Week 16 (early escape) or Week 24. Double-blind APR treatment continued to Week 52; patients could continue APR during an open-label, long-term treatment phase for up to 5 years treatment. Visits in years 2,3 , and 4 were scheduled at 13 -week intervals. Safety was assessed at each visit throughout the study, and results are summarized here by exposure.

Results: A total of 1493 patients were randomized and received $\geq 1$ dose of study medication (PBO: $n=495 ;$ APR30: $n=497$; APR20: $n=501$ ). At the 4-year data cut, the numbers of patients receiving APR30 and APR20 in each exposure period were 1441 in Weeks 0 to $\leq 52,1028$ in Weeks $>52$ to $\leq 104,865$ in Weeks $>104$ to $\leq 156$, and 767 in Weeks $>156$ to $\leq 208$. During the 0 - to $\leq 52$-week APR-exposure period, adverse events (AEs) occurring in $\geq 5 \%$ of APR30-exposed patients were diarrhea, nausea, headache, upper respiratory tract infection, and nasopharyngitis (Table). Most diarrhea and nausea AEs were reported within the first 2 weeks of treatment and usually resolved within 4 weeks; the frequency of gastrointestinal AEs decreased with longer APR30 exposure, and the frequency of other common AEs either decreased or remained stable with prolonged exposure (Table). Most AEs were mild/moderate in severity. During Weeks $>156$ to $\leq 208$ of APR exposure, the discontinuation rate due to AEs was $1.7 \%$ with APR30, and the rate of serious AEs (SAEs) was $7.0 \%$, consistent with earlier periods; most SAEs occurred in 1 patient each. Rates were very low for major cardiac events, malignant neoplasms, and serious opportunistic infections, comparable to the first year of treatment. Rates of depression remained very low in Weeks $>156$ to $\leq 208$. Marked laboratory abnormalities were infrequent, and most returned to baseline with continued treatment.

Conclusions: APR30 demonstrated a favorable safety profile and was well tolerated for up to 208 weeks, marked by the lack of accumulation of immunosuppression or need for specific laboratory monitoring. The incidence of AEs remained stable or decreased with long-term exposure to APR30.

Disclosure of Interest: P. Mease Grant/research support from: Abbott, Amgen, Biogen Idec, BMS, Celgene Corporation, Genentech, Janssen, Eli Lilly, Novartis, Pfizer, Roche, UCB, Consultant for: Abbott, Amgen, Biogen Idec, BMS, Celgene Corporation, Genentech, Janssen, Eli Lilly, Novartis, Pfizer, Roche, UCB, Speakers bureau: Abbott, Amgen, Biogen Idec, BMS, Genentech, Janssen, Eli Lilly, Pfizer, UCB, D. Gladman Grant/research support from: AbbVie, Amgen, BMS, Celgene Corporation, Janssen, Novartis, Pfizer, UCB, Consultant for: AbbVie, Amgen, BMS, Celgene Corporation, Janssen, Novartis, Pfizer, UCB, J. Gomez-Reino Grant/research support from: Roche and Schering-Plough, Consultant for: BMS, Pfizer, Roche, Schering-Plough, UCB, S. Hall Consultant for: Boehringer Ingelheim, MSD, Roche, Schering-Plough, Servier, Wyeth, Paid instructor for: Amgen, AstraZeneca, Boehringer Ingelheim, Centocor, GSK, MSD, Pfizer, Sanofi Aventis, Sanofi Pasteur, Schering-Plough, Serono, Wyeth, Speakers bureau: Boehringer Ingelheim, GSK, MSD, Pfizer, Roche, Sanofi Aventis, ScheringPlough, Wyeth, A. Kavanaugh Grant/research support from: Abbott, Amgen, AstraZeneca, BMS, Celgene Corporation, Centocor-Janssen, Pfizer, Roche, UCB, E. Lespessailles Grant/research support from: Amgen, Eli Lilly, Novartis, Servier, Speakers bureau: Amgen, Eli Lilly, Novartis, Servier, G. Schett Grant/research support from: Abbott, Celgene Corporation, Roche, UCB, Consultant for: Abbott, Celgene Corporation, Roche, UCB, M. Paris Employee of: Celgene Corporation, L. Teng Employee of: Celgene Corporation, J. Wollenhaupt Grant/research support from: Abbott, BMS, MSD, Pfizer, UCB, Consultant for: Abbott, BMS, MSD, Pfizer, UCB

DOI: 10.1136/annrheumdis-2017-eular.3840

\section{AB0786 SYSTEMATIC REVIEW OF MEASUREMENT PROPERTIES OF PATIENT REPORTED OUTCOME MEASURES IN PSORIATIC ARTHRITIS: A GRAPPA-OMERACT INITIATIVE}

P. Højgaard ${ }^{1,2}$, L. Klokker ${ }^{1}$, A.-M. Orbai ${ }^{2}$, K. Holmsted ${ }^{1}$, E.M. Bartels ${ }^{1}$, Y.Y. Leung ${ }^{2}$, N. Goel ${ }^{2}$, M. de Wit ${ }^{2}$, D. Gladman ${ }^{2}$, P. Mease ${ }^{2}$, L. Dreyer ${ }^{1}$, L.E. Kristensen ${ }^{1}$, O. FitzGerald ${ }^{2}$, W. Tillett ${ }^{2}$, L. Gossec ${ }^{2}$, P. Helliwell ${ }^{2}$, V. Strand ${ }^{2}$, A. Ogdie ${ }^{2}$, C. Terwee ${ }^{2}$, R. Christensen ${ }^{1,2}$ on behalf of GRAPPA-OMERACT PsA Core Set Working Group. ${ }^{1}$ The Parker Institute, Frederiksberg and Bisbebjerg Hospital, Copenhagen, Denmark, Frederiksberg, Denmark; ${ }^{2}$ GRAPPA-OMERACT PSA Core Set Working Group, International organisation,

Background: An updated psoriatic arthritis (PsA) core domain set (COS) for randomized controlled trials (RCTs) was endorsed at the Outcome Measures in Rheumatology (OMERACT) meeting in 2016 and reflects the patient and physician perspectives.[1]

Objectives: To synthesise the evidence on measurement properties of Patient Reported Outcome Measures (PROMs) in PsA in order to contribute to the development of a PsA core outcome measurement set (COMS) for RCTs adhering to the OMERACT filter 2.0 Framework.[2]

Methods: A systematic literature search was performed in EMBASE, MEDLINE and PsycINFO to identify studies published in English on PROM measurement properties in PsA. Two independent reviewers rated the quality of studies according to COnsensus-based Standards for the selection of health Measurement INstruments (COSMIN) guidelines,[3] extracted data on measurement properties and performed a qualitative evidence synthesis.

Results: Of 4703 identified references, 162 were read in full-text and 44 included in the systematic review (SR). Thirty-nine instruments, consisting of one or more scales, were analysed. PROMs measuring core set domains with at least fair quality evidence for good validity and reliability (and without evidence for inadequate measurement properties) were: Stockerau Activity Score for PsA (German) for the Musculoskeletal Disease Activity domain; the Psoriatic Symptom Inventory for Skin Disease Activity; the 36-Item Short Form Health Survey Physical Function scale and to a lesser extent the Health Assessment Questionnaire Disability Index and Bath Ankylosing Spondylitis Functional Index for Physical Function; the Psoriatic Arthritis Quality of Life Questionnaire, the Psoriatic Arthritis Impact of Disease questionnaire and VITACORA-19 (Spanish) for Health related Quality of Life/Life Impact; the Functional Assessment of Chronic Illness Therapy-Fatigue Scale for Fatigue, and the Social Role Participation Questionnaire for Participation. Evidence for content validity was lacking for most of these PROMs.

Conclusions: At least one PROM with some evidence for good validity and reliability was available for five out of eight inner circle domains of the PsA COS. Lack of content validity evidence constitutes a critical barrier for application to the PsA COS per the OMERACT Filter 2.0 Instrument Selection Algorithm [2]. This SR serves as a guide for additional research to increase knowledge of PROM measurement properties in PsA followed by stakeholder consensus for developing a PsA COMS.

PROSPERO:CRD42016032546

\section{References:}

[1] Orbai AM, de WM, Mease $P$ et al. International patient and physician consensus on a psoriatic arthritis core outcome set for clinical trials. Ann Rheum Dis 2016. doi: 10.1136.

[2] Martin Boers, John Richard Kirwan, Peter Tugwell et al. The OMERACT handbook. Updated May 2016, http://www.omeract.org

[3] Terwee CB, Mokkink LB, Knol DL et al. Rating the methodological quality in systematic reviews of studies on measurement properties: a scoring system for the COSMIN checklist. Qual Life Res 2012;21:651-7.

Disclosure of Interest: P. Højgaard Speakers bureau: Received speaking fees once from Celgene and UCB not related to the current work, L. Klokker: None declared, A.-M. Orbai: None declared, K. Holmsted: None declared, E. Bartels: None declared, Y. Y. Leung: None declared, N. Goel Employee of: QuintilesIMS, M. de Wit: None declared, D. Gladman: None declared, P. Mease: None declared, L. Dreyer: None declared, L. Kristensen: None declared, O. FitzGerald: None declared, W. Tillett: None declared, L. Gossec: None declared, P. Helliwell: None declared, V. Strand: None declared, A. Ogdie: None declared, C. Terwee: None declared, R. Christensen: None declared

DOI: 10.1136/annrheumdis-2017-eular.4631

\section{AB0787 STUDY OF SERUM SCLEROSTIN LEVELS IN ASSOCIATION TO ENTHESIAL ULTRASONOGRAPHY IN EGYPTIAN PSORIATIC ARTHRITIS PATIENTS}

R. Elmallah ${ }^{1}$, E. EL Attar ${ }^{1}$, D. Farrag ${ }^{1}$, D. Samaha ${ }^{2}$ on behalf of responsible for part of clinical measuring of sclerostin level. ${ }^{1}$ Rheumatology \& Rehabilitation; ${ }^{2}$ Clinical \& Chemical Pathology, Faculty of Medicine Ainshams University, Cairo, Egypt

Background: Psoriatic arthritis (PsA) is characterized by focal bone erosions and new bone formation, suggesting an uncoupling of osteoblast-osteoclast homeostasis [1]. Serum sclerostin is a protein inhibitor of wnt signaling pathway of bone formation implicated in the suppression of bone repair in inflammatory arthritis. The role of sclerostin in osteoimmunology and inflammatory arthritides is still controversial [2].

Objectives: This study aimed at measuring serum sclerostin in psoriatic arthritis men and to correlate its levels with disease activity scores, ultrasonographic findings and bone mineral density in those patients

Methods: This study included 30 male patients diagnosed with Psoriatic arthritis (PsA), 15 healthy age and sex matched volunteers as control group. Patients disease activity index measured. Clinical assessment by Leed's enthesitis Index (LEI) [3], Spinal manifestations scored according to Bath Ankylosing Spondylitis Activity Index [4], Serum sclerostin measured using enzyme linked immunosorbent assay. Ultrasonography of enthesis at Leeds enthesitis sites [5] and dual energy $x$-ray absorbiometry (DEXA) at the lumbar spine.

Results: The study included 30 PsA male patients with a mean age of $43.33 \pm 8.33$ mean, body mass index (BMI) of $26.87 \pm 2.63$ and 15 healthy age and sex matched

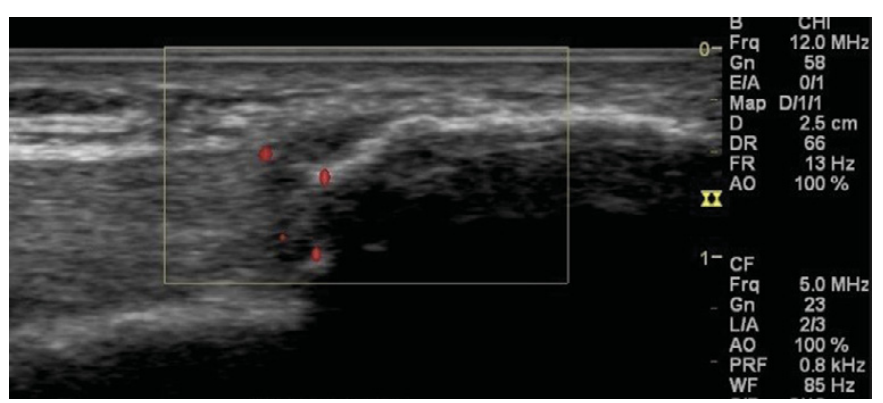

Figure 1. Ultrasonographic longitudinal scan of the tendoachillis showing hypoechoic area of edema \& power Doppler signal at insertion. 